\title{
FORTIFICAÇÕES DA BAÍA DA GUANABARA: MEMÓRIA COMO EDUCAÇÃO AMBIENTAL PARA MILITARES
}

\author{
Hermes de Andrade Júnior, Tamar Prouse de Andrade \& António Esteves Palma Rosinha
}

\begin{abstract}
RESUMO
O processo de construção do Brasil como nação deixou, em seus cinco séculos de história, um expressivo patrimônio, onde se destacam, particularmente, dezenas de fortificações espalhadas por todo o território brasileiro. Visando a preservar esses conjuntos arquitetônicos, vêm se multiplicando instrumentos legais dos órgãos do poder público voltados diretamente para a preservação do patrimônio histórico-cultural e ambiental. Objetivo. Usar a memória como exercício de construção de conhecimentos ambientais (educação ambiental) por parte de alunos militares que serviam no Forte do Leme. Metodologia. Entrevistas semi-estruturadas eficazes para levantar o processo da criação da APA-LEME e da revitalização da biota circundante degradada, sendo precursoras do elenco de mais documentos secundários que se revelaram fontes valiosas de esclarecimento de fatos. Resultados. A experiência de uso didático relacionado à memória do Leme, resgatada pelos depoimentos e experiências dos sujeitos entrevistados, permite um melhor conjunto avaliativo de atitudes militares de conservação e de catalogação da efetiva participação militar em operações do meio ambiente. A valorização do sistema de fortalezas, importante herança cultural, corrobora para ações voltadas para atividades turísticas, de preservação da memória, de educação ambiental e de intervenções ambientalmente conscientes.
\end{abstract}

\section{Palavras-Chave}

Educação ambiental; Forte do Leme; fortificações da baía da Guanabara;

patrimônio histórico e cultural; preservação ambiental

\section{GUANABARA'S BAY FORTIFICATIONS: MEMORY AS ENVIRONMENTAL EDUCATION FOR MILITARY PERSONNEL}

\begin{abstract}
In its five centuries of history, the process of building Brazil as a nation has left an expressive patrimony where dozens of fortifications are found throughout the Brazilian territory, particularly. Aiming at preserving these architectural ensembles, legal instruments have been multiplying from the organs of public power that are pointing directly towards the preservation of historical-cultural and environmental patrimony. Goal. Using memory as an exercise to build an environmental knowledge (environmental education) by military students who served in the Fort of Leme. Methodology. Effective semi-structured interviews were to lift the process of creating the APA-LEME and revitalizing the degraded surrounding biota, being precursors to the list of more secondary documents that proved to be valuable sources of factual clarification. Results. The experience of didactic use related to Leme's memory, rescued from the interviews and experiences of the interviewed people, allows a better evaluation of military attitudes of conservation and cataloging of effective military participation in environmental operations. The valorization of the fortress system, an important cultural heritage, corroborates actions aimed at tourism activities, preservation of memory, environmental education and environmentally conscious interventions.
\end{abstract}




\section{INTRODUÇÃo}

O processo de construção do Brasil como nação legou ao País, em seus cinco séculos de história, um expressivo patrimônio, onde se destacam, particularmente, dezenas de fortificações espalhadas por todo o território. Elas insistem em lembrar que reconhecer regiões, demarcar e defender fronteiras, construir cidades ou simplesmente assegurar-lhes a existência, não foi tarefa fácil e muito menos anônima ou aleatória. Embora muitas vezes sequer saibamos identificar seus autores ou reconhecer tal esforço, esse exercício repousa em um saber sobre as especificidades de uma terra nova que se mostraria capaz não só de desenhar o perfil de centenas de cidades, mas do próprio país, zelando pelos seus limites.

Capítulos inteiros dessa história necessitam ser escritos. A presença dessa ação construtiva, de planejamento e defensiva impõe-se ao olhar e pode-se dizer que muito cedo a Baía da Guanabara começou a guardar a memória disso em seus monumentos e em sua geografia.

Mas, o processo de crescimento e organização dos municípios, bem como dos ciclos de construção dos monumentos que marcam a paisagem das cidades, no caso das fortificações, comprometeu a própria visão de planejamento urbano e regional. Somada a questões mais estruturais, de certo modo, acabou permitindo, assim, formas de ocupação desiguais e desequilibradas em grandes trechos da orla da Baía, comprometendo inclusive o entorno ambiental. Neste sentido, as faixas proximais e junto às fortificações passaram também a ser percebidas como enormes reservas de áreas verdes e, neste sentido, as fortificações e seu entorno ganharam ao longo dos últimos anos uma grande importância, inclusive pela ótica do patrimônio.

O objetivo deste trabalho foi o de trazer a memória como exercício de construção de conhecimentos ambientais por parte de alunos militares que serviam no Forte do Leme, levantando as condições de criação da Área de Proteção Ambiental do bairro do Leme (APA- Leme, em 1990), na cidade do Rio de Janeiro.

$\mathrm{O}$ artigo é constituído por três seções. Na primeira, memória como construção e reconstrução de identidade, apresentam-se conceitos advindos da cultura. A segunda é metodológica, onde se destaca o uso da história oral como instrumento de sensibilização ambiental. Na terceira, são expressas categorias que dão vida à reconstituição da memória: historicidade, espaço e botânica, onde as evidências históricas e da natureza local em seu contexto dão corpo aos depoimentos dos entrevistados.

Resulta que a valorização do sistema de fortalezas, importante herança cultural, corrobora para ações voltadas para atividades turísticas, de preservação da memória, de educação ambiental e de intervenções ambientalmente conscientes. 


\section{A MEMÓRIA COMO CONSTRUÇÃo E RECONSTRUÇÃo DE IDENTIDADE}

A fortificação, qualquer que seja sua época, malgrado a rudeza de suas linhas, tem como obra de arquitetura militar uma expressiva beleza plástica. Grande parte delas no passado foi concebida por grandes arquitetos e artistas como Dürer, Miguel Ângelo, Francisco de Giogio Martini ou engenheiros militares conhecedores do vocábulo das formas clássicas que, embora de maneira econômica, na maioria dos casos, deixavam transparecer estes conhecimentos nos pórticos de entrada e portais das obras de defesa. A beleza das fortificações não repousa no seu repertório decorativo, mas na simplicidade e pureza de suas linhas onde, como regra geral, não se fazia concessão ao supérfluo. O desenho era escravo da função e por isto de uma sinceridade muito grande (Figura 1).

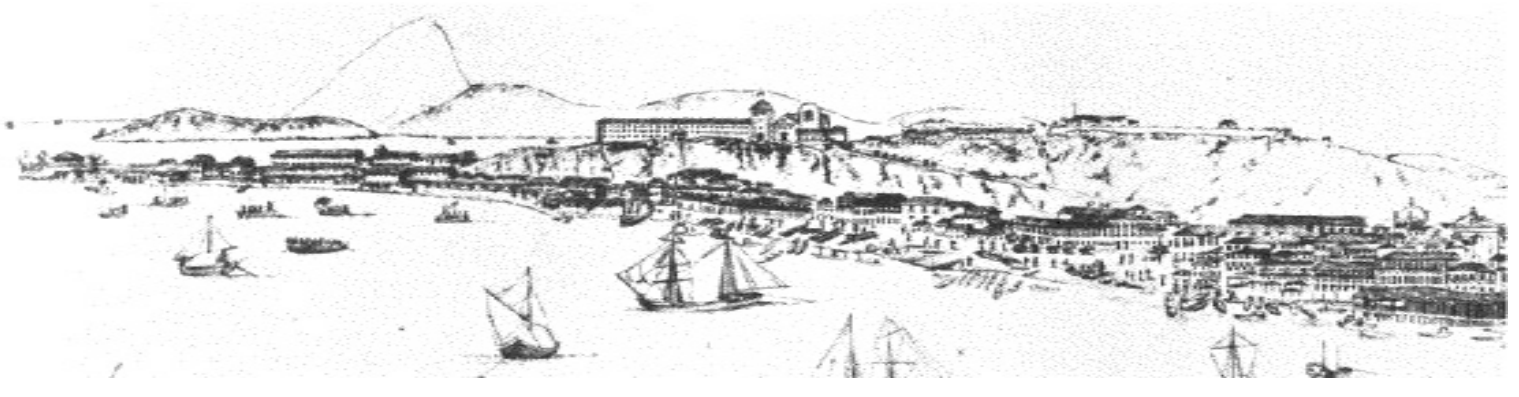

Figura 1: Enseada e porto do Rio de Janeiro

Fonte: IPHAN, Brasil

Longe do repertório estilístico, cujo gosto pode mudar com o tempo, as fortificações sobreviveram ao progresso mal compreendido, ao comércio sem alma ou aos administradores incultos e são motivos prediletos dos cartões postais, em virtude de serem referências na imagem da cidade.

A história da cidade do Rio de Janeiro, em seus primórdios, confunde-se com a História do Brasil, materializada e perpetuada através de seus monumentos, fortes e edificações restaurados e preservados. Durante o período colonial, diversas cidades brasileiras e dentre elas o Rio de Janeiro e a atual Niterói passam a acumular vestígios de uma ação constante de projeto e ampliação das estruturas defensivas, visando à proteção das cidades. Nos casos carioca e fluminense, a singularidade dessa arquitetura militar começa justamente em seu caráter dinâmico, uma arquitetura que é permanentemente colocada em avaliação e ajustada ao que lhe permitiria, por exemplo, manter a cidade invicta por quase cento e cinquenta anos, até o saque de Duguay-Trouin (1711) (Santos Júnior, 2010).

Entretanto, o que chama também a atenção, quando se observam as fortificações da Baía da Guanabara durante esse período, é o seu caráter de verdadeiro sistema defensivo-articulado/aberto, solução de grande complexidade, tendo em vista que, ao contrário dos exemplos europeus, as cidades brasileiras nunca foram dotadas de muralhas fechadas.

Essa particularidade local exigiria, em diferentes momentos históricos, uma acurada atenção para a localização, função e alcance de tiro de cada fortaleza de modo que 
cada qual, a despeito de seu papel e especificidade, funcionasse de modo integrado ao conjunto defensivo.

Ainda que, até as primeiras décadas do século XX, essa lógica "integrada" estivesse nas ampliações de algumas das fortificações da Baía, as ações administrativas desenvolvidas após a Independência e, sobretudo, com a República, viriam operar sucessivas fraturas na articulação e na unicidade desse conjunto de edificações, ao promover uma gradual e cada vez mais nítida separação entre as forças armadas e, por fatores decorrentes do próprio processo de urbanização, proceder à divisão do território do recôncavo da Baía da Guanabara em diferentes municípios, contribuindo indiretamente para uma percepção também fragmentária da história da ocupação da Baía e de seu sistema de defesa (Santos Júnior, 2010).

Em função do valor histórico de seu patrimônio, o Forte Duque de Caxias, localizado na área de proteção ambiental do morro do leme e que é datado aproximadamente a meados do século XVII, com reminiscências a meados do século XVI, foi criado por iniciativa do programa estratégico português de defesa da Baía da Guanabara.

A presente mobilização comunitária civil continua sendo de vital importância para assegurar identidades já esquecidas e seus direitos de cidadania. A preocupação de uma parcela da população de moradores do Leme, com as consequências danosas ao seu espaço circundando ao "Forte do Leme", suscita a existência de um projeto público que enseja o tombamento ecológico, fazendo surgir a voz de fiscais da natureza que usufruem dela constantemente.

Na mesma onda do estudo da memória coletiva, Halbwachs (2013) enfatiza a memória estruturada em identidades grupais lembrando que recordamos a nossa infância como membros da família: nosso bairro como membros da comunidade local, a nossa vida profissional em função da comunidade da fábrica ou do escritório, de um partido político e assim por diante, sendo tais recordações essencialmente memórias de grupo.

Halbwachs (2013) afirma que "a história é a compilação dos fatos que mais ocupa lugar na memória dos homens" (p. 100) e que "no geral, uma história começa a se extinguir uma tradição, não há um momento em que se apaga ou se decompõe uma memória social" (p. 101).

Le Goff aponta que "a memória coletiva é não somente uma conquista, é também um instrumento e um objeto de poder". São as sociedades cuja memória social é sobretudo oral ou que estão em vias de constituir uma memória coletiva escrita que melhor permitem compreender esta luta pela dominação da recordação e da tradição, esta manifestação da memória" (Le Goff, 1996, p. 472).

É esse mesmo processo que se pretende reviver: de rememorar e relembrar sujeitos históricos, ou mesmo de testemunhas da história vivida por uma coletividade que trazem um senso prático. Talvez até de ousar verificar em que circunstâncias o projeto de revitalização da mata atlântica chega a ser legitimado.

Desta forma, os depoimentos coletados tendem a demonstrar que a memória pode ser identificada como processo de construção e reconstrução de lembranças, nas condições de tempo presente. Em decorrência, o ato de relembrar insere-se nas possibilidades 
múltiplas de elaboração das representações e de reafirmação das identidades, construídas na dinâmica da história (Neves, 2000).

Este é o motivo para refazer a história, resgatando a memória contada por agentes que lutaram por preservar a paisagem e a natureza para as gerações futuras, no episódio do Morro do Leme e que a transformaram em uma Unidade de Conservação (UC), no processo explicado adiante.

\section{Metodologia}

Em 2001, através de contatos chegados ao autor, pertencente ao Grupo de Educação Ambiental da Universidade Federal do Rio de Janeiro (GEA/UFRJ) e travados por grupos de discussão sobre áreas de proteção ambiental no Rio de Janeiro, ocorreram reuniões mensais no Centro de Estudos de Pessoal do Exército (CEP), conhecido como "Forte do Leme". No Forte, houve moções para ações executivas, visando a formação de um conselho para gestão ambiental integrada das áreas de proteção ambiental (APAs) de Copacabana e do Leme. A entidade militar desponta na paisagem da região e desempenha hoje papel significativo de contenção da degradação local.

Este artigo é uma pesquisa bibliográfica e documental em que houve a oportunidade do uso da história oral breve através de entrevista exploratória, como instrumento de sensibilização ambiental de militares de um dos cursos de especialização do CEP.

Como parte do processo de sensibilização ambiental, nove alunos foram estimulados a procurar por pessoas locais que integravam a memória viva do processo de reflorestamento e de revitalização da biota circundante. Os alunos militares eram sargentos do exército, com idade média de 35 anos, provenientes de várias regiões geográficas brasileiras e alguns com formação acadêmica civil (quatro alunos). Localizaram três pessoas que gentilmente concordaram em serem entrevistadas. A finalidade principal das entrevistas foi exercitar e trazer a sensibilização ambiental a partir do comportamento e depoimento dos entrevistados. Agiram com base no objetivo de reconstituição de fatos, com entrevistas exploratórias realizadas pelo autor que viriam a compor com um elenco de palestras a militares do Forte do Leme, reconhecimento no terreno das espécies mencionadas no estudo e do manejo ambiental local assistido.

As entrevistas tiveram duração média de 30 minutos, sendo gravadas e posteriormente transcritas para serem analisadas. Tendo em vista os princípios éticos de pesquisa, os sujeitos foram esclarecidos do estudo em que participariam, sendo garantidos a eles todos os direitos relativos à pesquisa com seres humanos. Salvaguardaram-se suas identidades, tendo-lhes atribuído uma classificação identitária de E1, E2, E3.

Os depoimentos desses antigos agentes de preservação da APA-Leme e suas presenças foram importantes no processo de construção de atitudes de conservação ambiental dos militares envolvidos, uma vez que ajudaram a esclarecer motivações e as origens legais de sua constituição, manejada de 1987-1990. Na dinâmica resultante, alguns elementos ocultos da criação da APA-Leme e da revitalização da biota circundante degradada foram trazidos pelos agentes, como evidências complementares obtidas de 
fotografias e de documentos do acervo particular dos entrevistados, no tocante aos episódios de degradação e preservação ocorridos.

A opção pela técnica de entrevista semiestruturada deu-se em função de proporcionar ao entrevistador melhor entendimento e captação da perspectiva dos entrevistados, pois as entrevistas livres, ou seja, totalmente sem estrutura, onde os participantes da pesquisa falam livremente, tornam-se um "acúmulo de informações difíceis de serem analisadas que muitas vezes não oferecem uma visão clara da perspectiva do entrevistado" (Roesch, 1999, p. 159). Richardson (1999, p. 160) enfatiza que "é uma técnica importante que permite o desenvolvimento de uma estreita relação entre as pessoas e é um modo de comunicação no qual determinada informação é transmitida".

Também, o uso da entrevista semi-estruturada de caráter exploratório tem como vantagem a elasticidade quanto à duração, permitindo uma cobertura mais profunda sobre determinados assuntos.

Além disso, a interação entre o entrevistador e o entrevistado favorece as respostas espontâneas. Elas possibilitam aberturas e proximidade maior entre entrevistador e entrevistado, o que permite ao entrevistador tocar em assuntos mais complexos e delicados, ou seja, quanto menos estruturada a entrevista maior será o favorecimento de uma troca mais afetiva entre as duas partes. Desse modo, estes tipos de entrevista colaboram muito na investigação dos aspectos afetivos e valorativos dos informantes que determinam significados pessoais de suas atitudes e comportamentos. As respostas espontâneas dos entrevistados e a maior liberdade que estes têm podem fazer surgir questões inesperadas ao entrevistador que poderão ser de grande utilidade em sua pesquisa (Selltiz et al., 1987).

A memória foi aprofundada na ênfase de reconstrução de conceitos e de desconstrução de preconceitos ambientais, a partir de uma experiência de aula e de práticas: cada aluno militar teve a oportunidade de aprender pela dinâmica, motivação, atitude, vivência e pelos conceitos apresentados por depoentes experientes, interessados na preservação da área.

\section{RECONSTITUIÇÃO DA MEMÓRIA: HISTORICIDADE, ESPAÇO E BOTÂNICA}

\begin{tabular}{l}
\hline 1. Preservação da paisagem \\
\hline 2. Degradação da paisagem \\
\hline 3. Degradação da floresta \\
\hline 4. Impacto ambiental dos Fortes de guerra \\
\hline 5. Incêndios provocados \\
\hline 6. Ocupação dos morros com qualidade de vida \\
\hline 7. Criação da APA após reflorestamento \\
\hline 8. Ecoturismo ativo \\
\hline
\end{tabular}

Tabela 1: Categorias de análise emergentes relacionadas às atitudes ambientais

Os excertos das entrevistas que mais se relacionaram ao desenrolar de fatos, de evidências documentais e bibliográficas no tocante às atitudes para fins de conservação, 
revitalização e preservação, levaram às categorias emergentes (Bardin, 2011) constantes da Tabela 1.

\section{Preservação da paisagem}

Visando a preservar esses conjuntos arquitetônicos, vêm se multiplicando instrumentos legais dos órgãos do poder público voltados diretamente para a preservação do patrimônio histórico-cultural e ambiental. A proteção legal garante a manutenção e a valorização de suas características físicas, não descartando, porém, propostas de novos usos, desde que sejam compatíveis com a sua morfologia original. Por outro lado, a situação física e a localização privilegiada dessas fortalezas as transformam em patrimônio altamente valorizado em face do mercado imobiliário, viabilizando propostas de adaptações de usos autossustentáveis que possibilitem a formação de parcerias, apoios e patrocínios.

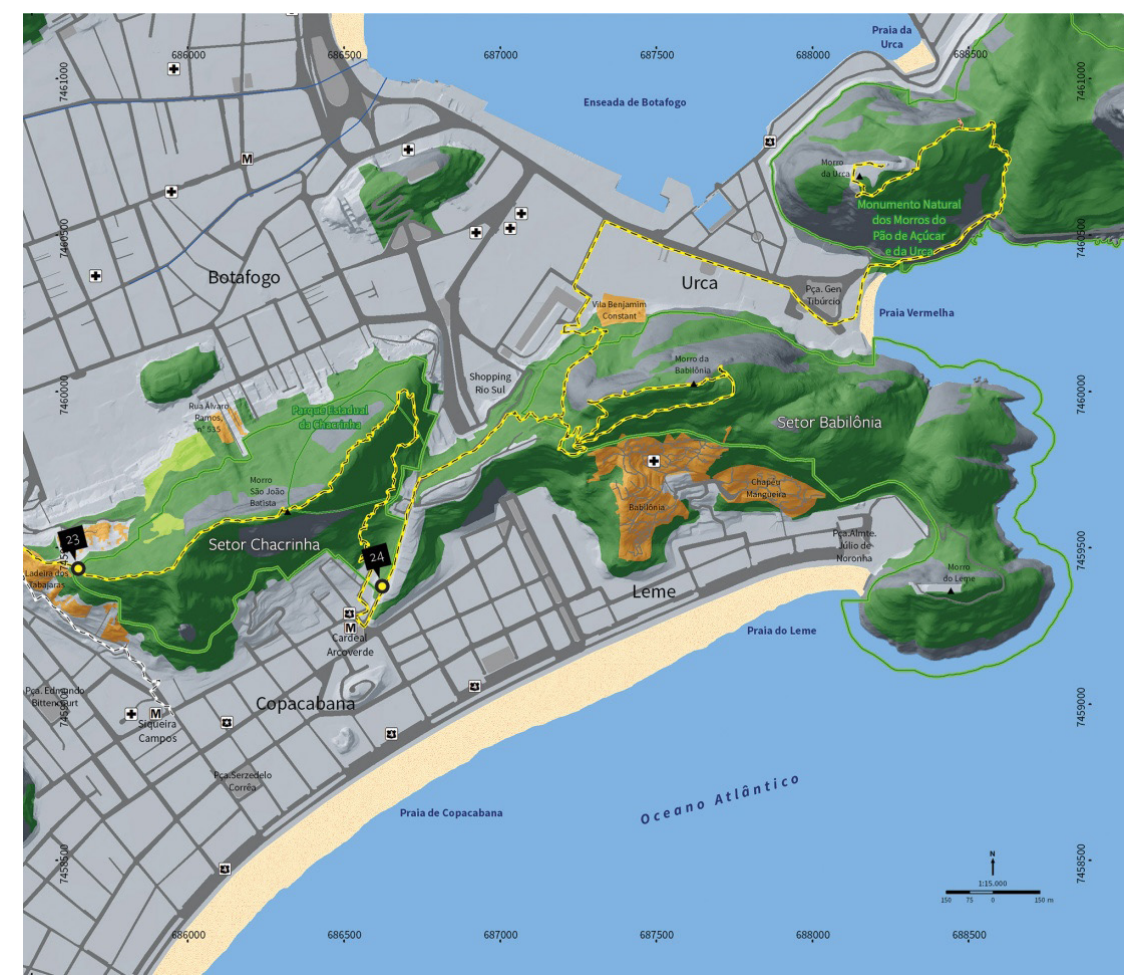

Figura 2: Situação dos Morros do Leme, Babilonia, São João e Urubu. Parque Natural Paisagem Carioca

Fonte: Trilha Transcarioca

Para melhorar a visitação, a Secretaria de Meio Ambiente e Conservação do Rio de Janeiro (SMAC) solicitou à Universidade Federal do Estado do Rio de Janeiro (UNIRIO) um estudo prevendo estratégias de gestão para três unidades de conservação (UC) cariocas justapostas e praticamente abandonadas pelo poder público: as Áreas de Proteção Ambiental - APA dos Morros São João e Babilônia e do Leme e Urubu e do Parque Estadual do Chacrinha (PEC). O resultado desse estudo (Sinay et al., 2012) fundamentou 
a criação em 2013 do Parque Municipal Natural da Paisagem Carioca pelo Decreto $N^{\circ}$ 37.231, sendo este o primeiro Parque criado no Brasil com base em estudos sociológicos/ turísticos e não nos aprofundados estudos biológicos, como de praxe até então (Figura 2).

\section{DEgRADAÇÃo DA PAISAGEM}

Para questões como a salinidade das terras secas e as perdas da biodiversidade, a resposta dos proprietários de terras como um todo é claramente insuficiente para travar os processos de degradação. E3 cita sua experiência com essa perda no morro do Leme: "plantamos melancia, abóbora. Tudo para combater o capim colonião e reflorestar. No final, plantávamos margaridão. Fazíamos daquilo um jardim de margaridão com mudas. Sabíamos que isso se perderia, mas o objetivo não era o margaridão, mas as mudas ..."

Para se recuperar, melhorar e preservar a capacidade produtiva de um solo, é necessária a utilização de práticas conservacionistas, cujo sucesso depende da conscientização e do esforço de toda a comunidade (Dumanski et al., 2006; Osaki, 1994; Pannell et al., 2006).

Recentemente, os órgãos de patrimônio cultural passaram cada vez mais a zelar por alguns desses monumentos, sobretudo à medida que as mudanças tecnológicas nas técnicas de defesa foram apontando para a incontornável obsolescência de suas funções e que a consciência ambiental foi mostrando-se alerta para temas como poluição, desmatamento, ocupação de encostas ou lixo. Assim, vêm sendo adotadas medidas protegendo um ou outro Forte e o seu entorno (Santos Júnior, 2010). No entanto, são incipientes ao ponto de ainda não terem a preocupação de desenhar um programa de ação e uma gestão ambiental integrada.

É fundamental ressaltar que os morros do Rio de Janeiro têm favelas de natureza variadas, apresentando perfil de menos ou para mais ecológicos, onde foram criadas Unidades de Conservação (UC) ambientais, configurando uma parte do espaço sócio-ambiental da cidade.

\section{DEGRADAÇÃo DA FLORESTA}

E1 faz seu comentário:

ano após ano, a floresta era queimada e ocupada pelo capim-colonião ( $p a-$ nicum maximum, capim africano que é combustível enquanto seco (...). Esse processo de degradação florestal começou no Morro da Babilônia, alastrando-se até o cume do Morro do Urubu e já ameaçava o Morro do Leme.

Programas ambientais têm procurado incentivar os proprietários a adotar práticas de conservação, principalmente por meio da divulgação de informações e processos sociais e, até certo ponto, mediante o pagamento de incentivos financeiros. Algumas práticas de conservação, tais como a aplicação de calcário para o tratamento de solos 
ácidos; a adoção do preparo reduzido (plantio direto); o cultivo em nível por meio da implantação de sistemas de curvas de níveis, terraços ou de barreiras de contenção de encostas; a implantação de sistemas de quebra ventos em áreas produção; o uso de sistemas de irrigação de baixo volume; o manejo de solo; a aplicação equilibrada de insumos químicos e a gestão cuidadosa de resíduos e dejetos, aliadas às práticas de conservação dos recursos naturais, como a conservação de nascentes, corpos d'água e de Áreas de Proteção Permanente (APP) têm sido a base de orientação dos serviços de extensão rural e de órgãos governamentais relacionados à gestão dos recursos hídricos.

Continua Er com sua narrativa:

tinha-se nesse local aproximadamente doze (12) hectares muito bem conservados de mata atlântica de costão rochoso com espécies nativas praticamente inalteradas até o episódio de incêndios (início do anos 1980) que se propagavam do Morro da Babilônia e que se direcionavam para o Morro do Urubu e também para a vertente que dá para a Pedra do Anel.

No Brasil, historicamente as unidades de conservação foram criadas especialmente para preservar os recursos naturais, evitando-se, sempre que possível, qualquer forma de uso da natureza. Acreditava-se que, por debaixo dessa redoma legal, a natureza estaria a salvo da sociedade. Incêndios provocados e propagados pelo capim-colonião potencializavam nos anos 1980 a destruição da paisagem que emoldura a Praia de Copacabana, o morro do Pão-de-Açúcar e o Forte Duque de Caxias, no pontal do Leme. E1 apresenta o quadro:

com base nos estudos da primeira área com o capinzal, produziu-se uma série de artigos voltados para o alerta "Mata do Leme pode pegar fogo", "Capim-colonião ocupa encosta do Forte antigo, Forte de Guerra", "A mesma área se recupera em sua vegetação, com mudas plantadas", "Comemoração das 2000 mudas plantadas", para se conseguir que "vingassem" o cultivo de outras espécies que não o capim colonião. Foram inúmeras as experiências realizadas com outros tipos de plantas e vegetação, até se conseguir uma que fosse ideal para o capim.

Paralelamente à devastação e ao reflorestamento dessa área, a cidade do Rio de Janeiro foi marcada nas últimas décadas pela expansão do crime, especialmente do narcotráfico. Além disso, estudos realizados nas últimas décadas indicavam que os "vazios" populacionais davam espaço à prática de outras atividades ilícitas como caça, captura e tráfico de animais silvestres, extração de recursos (madeira, minerais, palmito, etc.) e, no caso extremo do Rio de Janeiro, abrigo aos narcotraficantes. Durante esse período, várias UC cariocas foram utilizadas por criminosos para esconder drogas, armas e corpos e para assaltos, fatos que durante anos inviabilizaram a visitação pública. Nesse contexto, a percepção sobre o turismo e a visitação pública de forma geral começou a mudar. Os visitantes estão começando a ser vistos como "aliados" na fiscalização, pois, assim como os gestores, querem que a qualidade ambiental se mantenha ou melhore e 
estão dispostos a controlar (fotografar e denunciar) os desusos nas áreas naturais (Moraes \& Irving, 2013).

Desde 2009, foram instaladas Unidades de Polícia Pacificadora (UPP) nos morros da Babilônia, Chapéu Mangueira e Tabajara, motivados pela segurança internacional em grandes eventos. A criminalidade diminuiu significativamente nessas UC e o número de visitantes começou a crescer assim como as oportunidades de emprego e renda, tanto nas derivadas das atividades das trilhas de educação ambiental, de turismo e de lazer, como na estrutura de apoio, hotéis, restaurantes e pequenos pontos de comércio alimentício de rua (Sinay \& Pena, 2014).

O projeto de reflorestamento do Morro da Babilônia foi considerado um dos projetos mais bem sucedido do mundo desde o reflorestamento da Floresta da Tijuca, sendo apresentado como caso de sucesso na Rio+20. Esse reconhecimento, somado à instalação da UPP, despertou maior interesse do empreendimento, que desde então trabalha na divulgação de seu trabalho em uma área verde recuperada no coração da zona nobre do Rio de Janeiro.

\section{IMPACTO AMBIENTAL dOS FORTES DE GUERRA}

Em 1763, o Brasil passou à categoria de Vice-Reino, sendo a sede do governo transferida de Salvador para o Rio de Janeiro, o que aumentou sua importância e provocou maior cobiça de piratas, obrigando ao reforço nas defesas da Cidade. O marquês do Lavradio ( $2^{\circ}$ Vice-Rei, 1769-1779) esmerou-se na construção de várias fortificações.

Parte da Mata Atlântica foi removida para a construção das fortificações no topo dos Morros da Babilônia e do Leme e para a abertura de suas estradas de acesso conhecido como Caminho do Telégrafo (Cardoso, 1986) e a Estrada do Forte (com 1 km de extensão). Havia também a Bateria do Inhangá, que ficava no meio da praia, no Morro do Inhangá (Riotur, 1992, p. 18).

A necessidade de defesa do Rio de Janeiro dos invasores franceses, ingleses e holandeses, fez com que os morros fossem ocupados militarmente. Em 1710, o francês Duclerc desembarcou em Guaratiba. Atravessou Jacarepaguá e Camorim, sendo derrotado ao chegar à Cidade. Mas, em 1711, Duguay-Trouin invadiu a Baía da Guanabara com dezessete navios e a saqueou (Cruls, 1965, p. 133).

Com receio de nova invasão, em 1722, foi criado o Reduto do Leme, no Morro da Babilônia (CEP, 1990, p. 7). Ele se compunha de uma muralha de pedra com dois portões que fechavam o Desfiladeiro do Leme (Ladeira do Leme) junto ao Morro São João. Sua finalidade era defender esta entrada do Rio, dominando a estrada que ligava Copacabana a Botafogo. Ainda hoje, parte da muralha pode ser vista no local. Posteriormente, o Forte do Vigia, que hoje pertence à área do Centro de Estudos de Pessoal do Exército, foi guarnecido por uma Companhia de Dragões de Minas, tendo "Tiradentes", o Alferes Joaquim José da Silva Xavier, conforme a indicação de uma fonte, ali servido em 1789 poucos dias antes de sua prisão (CEP, 1990).

De fato, desde o século XVI, com a fundação da cidade de São Sebastião do Rio de Janeiro e da aldeia de São Lourenço, de um lado e de outro da Baía, a geometria de 
fortins e baluartes passou a pontuar a costa, assegurando, com suas bocas de fogo, tanto o movimento dos portos e o ir e vir das procissões religiosas, quanto o trabalho incessante dos engenhos situados na retaguarda rural.

A memória de um povo engloba os testemunhos de todas as instituições criadas pelos homens e toda e qualquer manifestação da sua criação. Neste acervo de memórias, as de caráter militar são importantíssimas para a história de cada nação, cabendo aos militares conservá-las como missão regimental e ética, mas também a toda comunidade, já que a memória cultural é um patrimônio de todos. E2 comenta:

esse patrimônio histórico, que nos foi legado com muito sangue derramado, representa diretamente a garantia de que continuará sendo efetiva a proteção e a conservação desta área. Em contrapartida, a permanência do exército neste local será mais um fardo a ser colocado sobre a intenção dos filões imobiliários que têm interesses meramente comerciais, sem dar importância à diversidade de espécies que dependem da preservação do local.

Além dos documentais escritos e iconográficos, dos objetos e artefatos militares, de maneira geral, destacam-se os edifícios militares, principalmente as fortalezas, que são presenças vivas da história e referências visuais na imagem da cidade, sendo marcos da evolução urbana e da história que está na afirmação de E2, neste excerto:

Sou a favor da presença do exército na área do Leme, porque em muito contribui para a preservação do local e, principalmente, pelo controle rígido em relação às pessoas que adentram na área protegida. A presença do exército no local foi de fundamental importância quando do reflorestamento dos morros, por ocasião dos incêndios provocados e pela existência da chamada patrulha patrimonial, responsável pelo controle do tráfego em áreas proibidas.

Desde o século XIX, a região inteira é radicalmente impactada por fortalezas e outros usos militares, pelo túnel Alaor Prata (que atravessa o Morro da Babilônia que une Botafogo à Copacabana), pelo metrô (que passa por baixo do Morro São João e do PEC), pelas favelas (da Chacrinha, removida na década de 1970, Chapéu Mangueira, Leme e Tabajara), pelos edifícios altos que mudaram a dinâmica dos ventos e dos pássaros e pelo despejo de lixo.

\section{INCÊNDIOS PROVOCADOS}

Nesse processo de ocupação, a mata nativa deu lugar a um capinzal que frequentemente se incendiava formando uma enorme e, por vezes, incontrolável fogueira. E2 afirma serem alguns pescadores da região em trânsito aos locais de pesca próximos do costão rochoso, os pontualmente responsáveis: "pois jogavam tocos de cigarro acesos e punham fogo de propósito no capim-colonião, a fim de melhorarem seu acesso à Pedra do Anel, aonde pescavam". 
Mas, os esforços para conter o capinzal que se propagava eram muitos, uma vez que ele multiplicava-se em taxa assustadora. E3 descreve um momento:

(...) Começamos a trabalhar e lembro-me de um dia de segunda-feira quando, na sexta-feira anterior, tínhamos roçado essa área oı. Meu operador de máquina, muito chateado, disse:

- 'Eu não aguento mais trabalhar, eu corto e essa coisa cresce'. Aí eu resolvi cortar uma touceira do capim colonião.

- 'Corta aqui!' E cronometrei. Em cinquenta e cinco minutos, ele já havia crescido uns quatro centímetros... Isso deu prá ver!

- 'Então, não adianta cortar! Vamos arrancar ele, vamos virar a touceira, colocar em leiras na mesma curva de nível, com a raiz para cima quebrada! (...).

Na década de 1990, a população do entorno foi incentivada a cooperar contra a degradação. E1 retrata que

na época, existia no local um estande de tiro no meio das elevações. $\mathrm{Na}$ ocasião, foi tudo desmatado para a sua construção. Mais tarde, ele foi abandonado e o capim cresceu rapidamente (capim-colonião), levando pessoas a colocarem fogo para abrirem pequenos caminhos para a pesca, na ponta do Emparatis e na ponta da Gameleira. O capinzal crescia demais e com isso a mata não regenerava a tempo, formando-se um círculo vicioso de crescimento e corte a cada dois ou três meses.

E1 também afirma que a área degradada começou a fechar-se pelo empenho no sentido de retirar o capim-colonião e por serem plantadas diversas mudas de árvores nativas da região.

A região era cheia de oportunidades, em função da vista panorâmica e de um clima praiano tropical. Festas animavam o povo com o uso frequente de pirotécnicos para fins promocionais. E1 enquadra assim:

em 1989/90, não houve eventos na rocha, só na praia. No Reveillon de 1991, uma churrascaria solicitou nova permissão para fixar um cabo de aço no alto da escarpa, para facilitar o espetáculo pirotécnico programado para a festa. No entanto, à tarde, uma estrutura em madeira com 49 metros quadrados foi içada com cabos, raspando a vegetação rupícola. A equipe que havia iniciado, há um mês, o trabalho de revegetação da área degradada nesta vertente, ao constatar o fato, solicitou auxílio ao exército que reforçou ser uma área de conservação ambiental. O responsável pela instalação afiançou "também ser ecologista" e que se houvesse algum risco, não acenderia os fogos. Saímos tranquilos com o trato. À meia-noite, começou o evento pirotécnico. Alguns minutos após, um pavio foi aceso do sopé do morro, levando fogo até o logotipo no meio da escarpa. Este fez a sua publicidade mas, estarrecedoramente, também incendiou quase toda a vegetação rupícola da área. 
Quanto aos fatores que alimentavam a degradação da área, E1 apresenta documentos (Senna, 1993a, 1993b) e comenta sobre cartazes comemorativos sob a vigilância da equipe do Projeto de Reflorestamento e Conservação Ambiental do Morro do Leme, recém-composta:

os eventos comemorativos realizados na escarpa trouxeram pontos positivos somente para seus organizadores, pois o ecossistema nativo sempre foi prejudicado. No reveillon de 1988, uma churrascaria solicitou permissão ao Centro de Estudos de Pessoal-CEP, do Exército, que é o proprietário da área, para colocar uma faixa na escarpa. Representava uma pomba branca saudando o Ano Novo. Para a passagem dos cabos que fixavam a faixa aos coqueiros do alto da rocha, desmataram a vegetação arbustiva que "atrapalhava" o ato. A equipe do Projeto de Reflorestamento e Conservação Ambiental do Morro do Leme procurou o então comandante do CEP, que imediatamente enviou uma patrulha para coibir o ato. Além disso, uma peça metálica que compunha a estrutura da faixa despencou lá do alto, indo cravar-se numa moita de vegetação, no meio da escarpa, ameaçando os transeuntes abaixo por meses a fio, até que um dia sumiu. A área desmatada foi logo ocupada por capim-colonião, que alguns meses após pegou fogo e matou um dos coqueiros-jerivá. Até hoje, passados cinco anos, a área está degradada, ameaçando com fogo a floresta adjacente.

Em visita recente feita ao local (2016), observa-se que pirotécnicos continuam a ser lançados, mas de forma mais recorrente a partir da praia. Com autorização dos comandantes dos fortes e fortalezas locais, também isso ocorre. Vez ou outra se percebe fogos e balões na direção dos morros e ainda os incêndios se dão na área, mas não tem a proporção de antes.

\section{OCUPAÇÃO DOS MORROS COM QUALIDADE DE VIDA}

Algumas favelas do Rio de Janeiro como Babilônia e Chapéu Mangueira podem ser consideradas favelas ecoturísticas, uma vez que suas associações de moradores têm interesse em ações de sustentabilidade, identificam-se na promoção da qualidade de vida, oferecendo uma proposta de turismo com consumo sustentável.

No entanto, a ideia das favelas ecológicas aparecerá somente no contexto dos megaeventos direcionados por políticas públicas majoritárias relacionadas à Conferência da ONU em 2012 (Rio+2O), a qual amplificou as atrações turísticas.

Na Babilônia, entre os anos 1930 e 1940, o crescimento se deu pelos soldados do Forte do Leme de baixa patente, que não tinham condições de morar no Leme ou em Copacabana e que construíram suas casas espaçosas e com quintais no alto do morro. O Chapéu Mangueira, que é um morro ao lado, apresenta casas menores e mais densas, como resultado da expansão entre os anos 1940 e 1950, quando migrantes de Minas Gerais e estados do Nordeste vieram para o Rio de Janeiro para trabalhar na construção civil dos bairros de Copacabana e Ipanema. 
Como vimos, todas essas favelas receberam uma Unidade de Polícia Pacificadora (UPP), que despertou maior interesse em promover e estimular a visitação à área de reflorestamento.

E1 reconhece a importância de sensibilizar os moradores para conter a devastação:

com o corte do capim-colonião e mantendo a área limpa, a propagação de incêndios era bem menor. A Secretaria de Desenvolvimento Social, contratando trabalhadores da favela para o serviço de reflorestamento acima da favela do Chapéu Mangueira e da Babilônia incentivou o Projeto Mutirão, que tinha a missão de reflorestar o lado que estava na favela. Desta área partiam focos de incêndios e acreditava-se que, como os trabalhadores eram da favela, eles se empenhariam mais na consciência de preservação do local, tomando gosto pelo trabalho e cobrando dos moradores um comprometimento maior.

O Projeto Mutirão (1981-1984) tinha por objetivo promover a expansão de serviços públicos para cerca de 150 favelas, com participação da população local no processo de planejamento e implementação. As obras eram realizadas com mão de obra voluntária e voltadas para construção de infraestrutura, saneamento básico, reformas e construções de creches. Essas ações do Mutirão foram objeto de interesse de ilustres visitantes como Jimmy Carter, em 1984 e a Princesa Anne, em 1986 (Bottino, 2016).

Em 1986, foi criado um desdobramento do Projeto Mutirão, subprojeto Mutirão Reflorestamento, voltado para a contenção de encostas, a recuperação de vegetação, nascentes e mananciais e reposição da paisagem. Segundo a Prefeitura da Cidade do Rio de Janeiro (2008), o Programa Mutirão Reflorestamento teve início efetivamente em 1987. Um dos mais conhecidos mutirões de reflorestamento é o da Babilônia e Chapéu Mangueira, iniciado entre o final dos anos 1980 e início dos anos 1990.

Pelos registros da Associação de Moradores da Lauro Müller e Adjacências (ALMA), nos anos 1980, a expansão da ocupação no morro agravou os incêndios provocados pela extensa cobertura de capim colonião. Os incêndios tornaram-se um risco para os moradores das favelas, mas prejudicavam também o Shopping Rio Sul e os moradores das ruas Lauro Müller e Ramon Castilha, representados pela ALMA, em Botafogo.

Todos os entrevistados (E1, E2, E3) afirmaram que as equipes trabalharam duro contra as causas dos incêndios e com técnica para o sucesso da empreita, que teve uma motivação e logística integradas.

\section{CriaÇÃo da APA APós REFLORESTAMENTO}

Além de originais exemplares da flora em mais de 12 hectares de Mata Atlântica típica de afloramento rochoso do litoral que foram mantidos em bom estado pela utilização seletiva da área, mais de 80 espécies de aves que procuram abrigo, alimento ou pouso tem transitado no local. Destacam-se: tié-sangue, saíra-azul, sabiá, gavião-carijó, cambaxirrão (com seu canto forte), dentre outras. 
As UC no Rio de Janeiro estão protegidas especificadamente pelo Decreto Estadual $N^{\circ}$ 2.853/69 que criou o Parque Aldir de Castro Dantas, vulgo "Chacrinha" (PEC), com o objetivo de designar uma área para a coletividade dos bairros de Copacabana e Leme, que leva em consideração a densidade demográfica local e a preservação do ecossistema natural, permitindo pesquisas, desenvolvimento de atividades de educação e interpretação ambiental, de recreação, em contato com a natureza, e de turismo ecológico; pelo Decreto Municipal N 14.874/96 que estabeleceu a Área de proteção ambiental (APA) dos Morros da Babilônia e de São João, com o objetivo de recuperar e recuperar a cobertura vegetal existente, preservar e asilar exemplares raros, endêmicos, ameaçados de extinção ou insuficientemente conhecidos da flora e fauna, proteger sítios de excepcional beleza e valor científico, estimular às atividades de lazer, quando compatíveis com os demais objetivos da APA e proteger e valorizar o entorno do bem natural tombado.

Com o reflorestamento, sucedeu-se à proposta de tombamento ecológico desta APA ao governo do estado do Rio de Janeiro. E1 afirma: "as muitas reuniões que tivemos e as horas que passamos em campo poderiam ser esquecidas facilmente. Por isso, usamos nossos contatos e pessoas influentes que tínhamos para chegar o assunto ao Governador do Estado".

O Decreto Municipal n. 14.008/1995 criou a APA do Morro do Leme, Urubu e llha de Cotunduba e proibiu o parcelamento do solo, em todo território da UC, de todas as atividades degradantes ou potencialmente degradantes, novas construções, com mudança no gabarito, na volumetria ou no uso das edificações existentes. E2 diz que:

Foi um dia de grande alegria para mim, quando vi aquele documento que criava os limites da área em que houve tanta gente envolvida e tanto suor. Senti-me recompensado pelo esforço reconhecido. Me emocionei.... Comemorei muito com meus amigos e colegas de trabalho!

E3, por sua vez, afirma: "nunca esperei pelo reconhecimento imediato, porque em minha profissão aprendi que a natureza responde lentamente, mas firmemente. Fizemos a proposta da APA sair do papel, antes dela ter um papel!"

O Cadastro Nacional das Unidades de Conservação (CNUC) trouxe um avanço notável com participação popular nos últimos dez anos, desde a criação do Sistema Nacional de Unidades de Conservação (SNUC). No entanto, as novas áreas protegidas ainda caracterizam que o Brasil seja o que menos gasta com ele, comparado com outros países tidos como referência no contexto da conservação, como África do Sul, Austrália, Canadá, Costa Rica, Estados Unidos, Nova Zelândia. Exemplificando, enquanto o Brasil gasta, em média, cerca de 4 dólares por hectare, os EUA destinam US\$78/ha, a África do Sul US\$34/ha e a Costa Rica US\$18/há. (Medeiros \& Araújo, 2011, p.153, 57). Estas áreas do Rio de Janeiro e hoje legalmente protegidas foram organizadas, desde a criação, por diferentes entidades, destacando-se a Cooperativa de Trabalhadores em Reflorestamento da Babilonia (CoopBab), ONG Florescer, Exército Brasileiro (EB) e Grupo de Ação Ecológica (GAE), dando início ao reflorestamento das áreas. 


\section{ECOTURISMO ATIVO}

Visitantes e gestores entrevistados anseiam pela promoção do turismo sustentável, pela educação ambiental, pelo incentivo ao desenvolvimento de pesquisas científicas, pela captação de mais recursos para a melhoria das estruturas existentes e pela promoção das UC dando Ihes maior visibilidade turística. Entre os motivos de visitação apontados pelos entrevistados destacam-se a infraestrutura (do PEC), as caminhadas nas trilhas, passeios com crianças, repouso, festas, contato com a natureza, vistas deslumbrantes da cidade, as vias de escaladas, o futebol e a pesca.

Para E2 "o local do Forte do Leme é maravilhoso em todos os aspectos. Acho que se os militares também são forem guias de visita com treinamento e com educação ambiental, todos ganhamos".

Quanto às trilhas, O PEC com uma área total de 13,3 hectares de Mata Atlântica possui uma trilha de 1260 metros que pode ser percorrida em aproximadamente $40 \mathrm{mi}$ nutos. O esforço físico requerido para este percurso não é forte o que classifica a trilha como leve, especialmente por estar quase todo o percurso coberto por árvores o que ameniza a caminhada por um terreno quase todo plano. A trilha do Morro São João tem um percurso de 2800 metros a ser realizado em 2 horas. Por alcançar uma elevação de 384 metros, o esforço realizado é moderado e a trilha é qualificada da mesma forma. As trilhas dos Morros Leme e Urubu pode ser completadas em 1 hora, alcançando 158 metros de altura e a do Morro da Babilônia, que alcança 150 metros de altura e cujo trajeto pode ser feito em uma hora e meia, são também classificadas como moderadas, pois partes delas estão expostas ao sol exigindo maior esforço dos visitantes. Apenas a trilha do Morro da Babilônia tem placas informativas, enquanto as restantes ou possuem sinalização escassa ou não possuem qualquer sinalização. Quanto aos impactos negativos sobre o meio ambiente associados à visitação, nas entrevistas foram apontados o acúmulo de lixo, a erosão e a compactação do solo, a destruição de placas de sinalização existentes. Em visitas a campo apenas os dois primeiros impactos foram efetivamente observados (Sinay \& Pena, 2014).

\section{Conclusão}

A experiência de educação integrada com as palestras a militares do Forte do Leme, o reconhecimento no terreno das espécies mencionadas pelos entrevistados e do manejo ambiental local assistido por eles, foram importantes e significativas para todos os presentes. Os alunos militares do Exército Brasileiro que passaram pelo processo de sensibilização ambiental conviveram com os agentes entrevistados, tendo contato com a realidade descrita e vivida por eles e receberam deles argumentos e exemplos de atitudes favoráveis à preservação ambiental advindas de (1) uma carga cognitiva, pelas informações relativas ao monitoramento e manejo ambiental de parte da área militar sobre a qual desconheciam os detalhes e que mostravam ângulos da validade do papel do exército como importante no processo de revitalização; (2) um reforço psicológico positivo, propiciado pelas interações com agentes ambientais dotados de consciência 
ecológica em conduta exemplar; e (3) uma desconstrução simbólica do preconceito e do relativismo com que os agentes ambientais eram entendidos. No tocante à sensibilização e preservação ambiental, essa iniciativa com militares favorece novos episódios de educação progressiva de militares por parte de civis, aonde haja a necessidade de interação militar-civil para a preservação, a exemplo do que se deu em parte da área relativa ao memorial descritivo do terreno ocupado pelo Centro de Estudos de Pessoal do Exército e pelo Forte do Leme, onde estão presentes ruínas de fortins e de antigos postos de observação.

Os resultados apontam para a necessidade de desenvolver atividades de natureza ambiental com o público local e com o turista em geral com o provimento de atitudes de preservação nas áreas abrangidas pelos fortes da Baía da Guanabara. Tais atividades poderiam ser marcadas pela parceria com entidades e grupos ambientais, representada por esta experiência relatada de uma série delas, visando reduzir o impacto ecológico em função do turismo. Finalmente, a valorização do sistema de fortalezas, importante herança cultural, revela parte significativa de nossa história e, com certeza, corrobora ações voltadas para atividades turísticas, de preservação da memória, de educação ambiental e de intervenções ambientalmente conscientes.

Espera-se que tal experiência de uso didático relacionado à memória do Leme, resgatada pelos depoimentos e experiências dos sujeitos entrevistados, permita um meIhor conjunto avaliativo de atitudes militares de conservação e de catalogação da efetiva participação militar em operações do meio ambiente. A proximidade do adensamento populacional das instalações de um Forte de guerra (Forte Duque de Caxias), ainda mais intensifica a ideia de reforço da memória como motivo de sua própria sobrevivência enquanto identidade de grupo.

\section{REFERÊNCIAS}

Andrade Junior, H. (2000). Educação ambiental: sensibilização populacional e desenvolvimento sustentável. In S. da Mata et al. (Eds.), Educação ambiental: compromisso com a sociedade (pp. 11-18). Rio de Janeiro: MZ editora.

Bardin, L. (2011). Análise de conteúdo. SP: Edições 70.

Bottino, C. M. M. (2016). Quem descobriu a favela? A trajetória das agências de turismo nas favelas cariocas. Dissertação de Mestrado Profissional, CPDOC, Rio de Janeiro, Brasil. Retirado de http:// bibliotecadigital.fgv.br/dspace/handle/10438/17655

Cardoso, E. et al. (1986). Copacabana, história dos bairros. Rio de Janeiro: João Fortes Engenharia.

Centro de Estudos de Pessoal do Exército (CEP). (1990). Ementa das origens do Forte Duque de Caxias (17081990). Rio de Janeiro: Memoteca.

Cruls, G. (1965). Aparência do Rio de Janeiro. Rio de Janeiro: José Olympio Editora, v.1.

Dumanski, J., Peiretti, R., Benites, J. R., Mcgarry, D. \& Pieri, C. (2006). The paradigm of conservation agriculture. In Proceedings of World Association of Soil and Water Conservation (pp. 58-64). Retirado de https://www.researchgate.net/publication/284061910_The_paradigm_of_conservation_tillage 
Halbwachs, M. (2013). A memória coletiva. São Paulo: Ed. Centauro.

Le Goff, J. (1996). História e memória. São Paulo: Unicamp.

Medeiros, R. \& Araújo, Fábio F. (Eds.) (2011). Dez anos do sistema nacional de unidades de conservação da natureza: lições do passado, realizações presentes e perspectivas para o futuro. Brasília: MMA.

Moraes, E. A. \& Irving, M. A. (2013). Ecoturismo: encontros e desencontros na reserva extrativista do Cazumbá, Iracema (AC). Revista Brasileira de Ecoturismo, 6(3), 738-757.

Neves, L. de A. (2000). Memória, história e sujeitos: substratos da identidade. Revista História Oral, 3 , 109-115.

Osaki, F. (1994). Microbacias: práticas de conservação de solos. Curitiba: Paraná.

Pannell, D. J., Marshall, G. R., Barr, N., Curtis, A., Vanclay, F. \& Wilkinson, R. (2006). Understanding and promoting adoption of conservation practices by rural landholders. Australian Journal of Experimental Agriculture, 46(11), 1407-1424.

Prefeitura da Cidade do Rio de Janeiro. (2008). Mutirão reflorestamento: 20 anos. Rio de Janeiro.

Richardson, R. J. (1999). Pesquisa social: métodos e técnicas. São Paulo: Atlas.

Roesch, S. M. A. (1999). Projetos de estágio e de pesquisa em administração: guias para estágios, trabalhos de conclusão, dissertações e estudos de casos. São Paulo: Atlas.

Riotur. (1992). Copacabana, 1892/1992: subsídios para a sua história. Rio de Janeiro: Secretaria Municipal de Cultura.

Santos Júnior, J. C. (2010). Plano de revitalização e uso turístico-cultural das fortificações históricas da baía de Guanabara. VI Seminário Regional de Cidades Fortificadas e Primeiro Encontro Técnico de Gestores de Fortificações, UFSC: Florianópolis. Retirado de http://cidadesfortificadas.ufsc.br/ files/2011/03/2010_6sem_palestra_JoseClaudioSantos/r.pdf

Selltiz, C. et al. (1987). Métodos de pesquisa nas relações sociais. São Paulo: EPU.

Senna, P. (1993a). Ocupação humana, alteração ambiental e conservação da natureza no bairro do Leme. Monografia de curso de especialização, Pontifícia Universidade Católica do Rio de Janeiro, Rio de Janeiro, Brasil.

Senna, P. (1993b). Impacto ambiental causado por eventos comemorativos na escarpa rochosa do Morro do Leme, Rio de Janeiro. Revista Albertoa 3(15), 141-152.

Sinay, L. et al. (2012). Uma proposta estratégica para o ótimo aproveitamento turístico dos Morros da Babilônia, São João, Leme e Urubu e do Parque Estadual da Chacrinha. Rio de Janeiro: Universidade Federal do Estado do Rio de Janeiro.

Sinay, M.C. \& Pena, I. A. B (2014). Parque Natural Municipal da Paisagem Carioca (RJ): ecoturismo e sustentabilidade. Revista Brasileira de Ecoturismo, 7(3), 500-516.

Telles, F. P. et al (s.d.). Coleta de dados que subsidiem a avaliação dos projetos de reflorestamento para o bairro do Leme, RJ, visando a possibilidade de sua ampliação. Mimeo. 


\section{NOTAS BIOGRÁFICAS}

Hermes de Andrade Júnior - Licenciado em Relações Internacionais e também em Ciências Militares (Academia Militar das Agulhas Negras), com mestrado em sociologia e um doutorado em saúde pública, com ênfase na sociedade e no meio ambiente. Faz pós-doutorado na Universidade Católica de Portugal, sendo pesquisador sênior do Centro de Estudos Filosóficos e Humanísticos da Universidade em Braga (CEFH/UCP).

Email: handradejunior@gmail.com

Morada: Universidade Católica, Campus Regional de Braga, Faculdade de Filosofia e Ciências Sociais, Centro de Estudos Filosóficos e Humanísticos (CEFH/UC). Rua de Camões, Braga, 4710-362, Portugal

Tamar Prouse de Andrade - Mestranda da IMF / UCJC, Espanha. Jornalista, gestora da Liblikas Sustainable. Sócia fundadora da Sociedade de amigos da área de proteção ambiental do morro do Leme (SOAPA-Leme), Rio de Janeiro, Brasil.

Email: tprouse@gmail.com

Endereço: Universidad Camilo Jose Cela, Calle Castillo de Alarcón, 49, 28692 Villanueva de la Cañada, Madrid, Espanha

António Esteves Palma Rosinha - Licenciado em Ciências Sócio-Militares pela Academia Militar de Portugal e em Psicologia/Orientação e Desenvolvimento de Carreira pela Faculdade de Psicologia da Universidade de Lisboa. Doutor em Psicologia dos Recursos Humanos, do Trabalho e das Organizações pela Faculdade de Psicologia da Universidade de Lisboa. Investigador do Centro de Investigação em Psicologia da Faculdade de Psicologia da Universidade de Lisboa (CIPUL).

E-mail: antonio.rosinha@sapo.pt

Endereço: Instituto Superior de Comunicação Empresarial (ISCEM), Praça do Príncipe Real, 27, 1250-184 Lisboa, Portugal

* Submetido: 28-02-2018

* Aceite: 22-06-2018 